\title{
Environmental Complexity and the Drifting Behaviour of a Running Water Amphipod
}

\author{
D. Dudley Williams and Kathryn A. Moore \\ Division of Life Sciences, Scarborough Campus, University of Toronto, 1265 Military Trail, Scarborough, Ont. M 1C 1A4
}

Williams, D. D., and K. A. Moore. 1989. Environmental complexity and the drifting behaviour of a running water amphipod. Can. J. Fish. Aquat. Sci. 46: 1520-1530.

\begin{abstract}
Overall level and type of activity of Gammarus pseudolimnaeus changed with current speed and pattern in laboratory stream tanks. With increasing current speed (15 to $28 \mathrm{~cm} / \mathrm{s}$ ) active and passive downstream transport increased, whereas numbers of animals moving upstream decreased. Upstream movement increased in smooth and rough flow above $28 \mathrm{~cm} / \mathrm{s}$. Mean swimming speeds of individuals differed between day and night at most current settings. Total distances drifted by single animals were greater in 43-L ("macroenvironments") than in 3.5-L stream tanks ("microenvironments"), and were greater in both environments at night. On average, individuals had 6.8 drift episodes during $12 \mathrm{~h}$ darkness in microenvironments (nightly downstream displacement $3.04 \mathrm{~m}$ ), compared with 37.9 episodes in macroenvironments (displacement $22.4 \mathrm{~m}$ ). Level of activity was positively related to amphipod benthic density during both day and night in microenvironments; however, in macroenvironments, at night, the relationship was negative. Cessation of drift in the presence of fish predators and marked nocturnal activity peaks in macroenvironmentswere absent in microenvironrnents. The differentresponses within the two environments may reflect differences in perception of local environmental scale by the amphipods. This process may occur during the periodic contacts that animals make with the substrate during drift; individuals may retain some familiarity with features of their immediate surroundings.
\end{abstract}

Des études menées en laboratoire dans des bassins ont montré que le niveau global d'activité et le type d'activité de Gammarus pseudolimnaeus, varient en fonction de la vitesse et du type de courant. Quand la vitesse du courant augmente (15 à $28 \mathrm{~cm} / \mathrm{s})$, le deplacement actif et passif des gammares augmente tandis que le nombre de gammares qui se déplacent A contre-courant diminue. Le deplacement des gammares A contre-courant augmente dans des condiitions d'écoulement laminaire et turbulent A des vitesses de courant supérieures à 28 $\mathbf{c m} / \mathbf{s}$. Dans la plupart des conditions de courant, les vitesses moyennes de nage des individus n'étaient pas les mêmes le jour et la nuit. Les distances totales parcourues par les individus étaient supérieures dans le bassin de 43-L ("macromilieu») à celles parcourues dans les bassins de 3,5-L ("micromilieu»); elles étaient aussi supérieures, dans les deux milieux, durant la nuit. En moyenne, le nombre de périodes de derive des gammares durant les $12 \mathrm{~h}$ de nuit était de 6,8 dans le micromilieu (deplacementnocturne vers l'aval de 3,04 m), comparé A 37,9 périodes dans le micromilieu (deplacement de $22,4 \mathrm{~m}$ ). Dans les micromilieux, le niveau d'activité augmentait avec la densité des amphipodes au fond des bassins aussi bien le jour que la nuit; cependant, dans les macromilieux, cette relation était inversée durant la nuit. Dans les micromilieux, il n'y avait pas arrêt des déplacements quand des poissons prédateurs étaient introduits dans le bassin et nous n'avons pas observe de maximums d'activité prononcés durant la nuit comme il a été observe dans les macromilieux. Les differences de comportement qui ont été observées dans les deux milieux pourraientêtre attribuables à des differences relatives à la perception qu'ont les amphipodes de leur environnement. Ce processus pourrait avoir lieu durant les contacts périodiques que les gammares ont avec le substrat au cours de leur déplacement : les caractéristiques de l'environnement immédiat des gammares pourraient determiner leur niveau d'activité.

Received/uly 25, 1988

Accepted May 16, 1989

(J9817)

D espite several decades of research examining stream drift, both in the field and laboratory (Waters 1972), much remains that we do not understand about the role of physical and biological factors in controlling the drift process (Statzner et al. 1984). Several abiotic factors are known to correlate with drift density, these are discharge, water temperature, and photoperiod, but field measurements or experiments involving these factors often produce contradictory results (e.g. Andersson et al. 1986; Culp 1986; Perry and Perry 1986; Statzner et al. 1987). These inconsistencies may be partially due to qualitative and quantitative differences in the composition of benthic communities between streams (D.D. Williams, unpubl. data).

There is also a behavioural component to drift, as many species apparently show an active determination to enter and leave
Reçu le 25 juillet 1988 Accept6 le 16 mai 1989 the water column with a definite periodicity (Müller 1974). This component may differ in intensity among species. "Behavioural drift" may be supplemented or, over-shadowed by animals drifting as the result of various abiotic factors such as the above mentioned. This had led to the proposal of additional categories of drift. For example, "catastrophic drift" results fromphysical disturbance of the benthos while "constant drift" occurs more or less continually, but at low level, and may represent animals that accidentally lose their grasp on the stream bed (Minckley 1964; Waters 1965; Williams and Levens 1988). However, another component of "constant drift" in some species may result from voluntary, aperiodic release from the substrate. There may be a behavioural component to "catastrophic drift" as well. Terms have become ambiguous as authors have wrestled with trying to decipher whether or not entry into the 


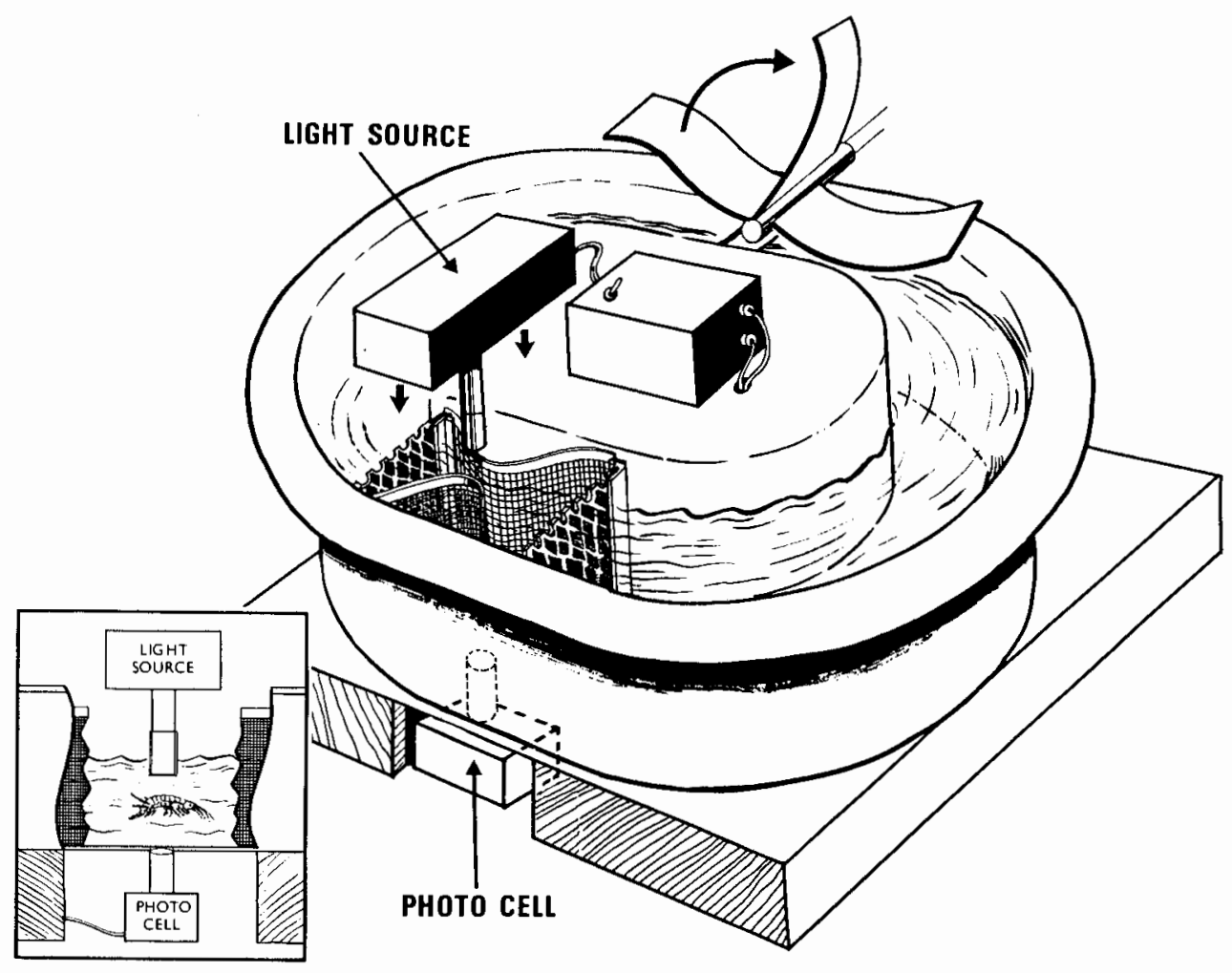

FIG. 1. Diagram of a large activity tank.

drift is an intentional act by an organism. It may be that a single drift episode is comprised of more than one component phase, each affected by different factors, perhaps operating independently. One component might be "entry into the drift", a second, "transport in the water column", and a third, "termination of drift". Each component may be controlled by different behavioural and/or environmental factors. For example, "entry" could be initiated by erosion, whereas "transport" may be more associated with hydrodynamics. Reestablishment on the stream bed during "termination" could be the result of the animal swimming towards the bed (behavioural) or being passively carried towards the bed by gravity or current (environmental). Our future understanding of the causes of drift requires an integrated, experimental approach recognizing that many factors, acting both simultaneously and independently, may be responsible (Wiley and Kohler 1984).

Laboratory experiments in which single species are subjected to the systematic manipulation of environmental variables may contribute to the unravelling of the complexity of factors governing stream drift (Corkum et al. 1977; Williams and Moore 1982). They also may reveal the relative importance of the different types of drift and compensatory upstream migration (Bishop and Hynes 1969).

The purpose of this study was to examine the activity response of a lotic invertebrate (Gammarus pseudolimnaeus Bousfield) to laboratory manipulation of local environment and to determine whether drift response could be used to assess the animal's ability to perceive scale in its surroundings. This was done by seeking answers to the following specific questions: (1) do activity level and type change at different current speeds and flow patterns? (2) are there differences in distances moved in the water column ("transport") according to size of environment, and do these vary with light conditions? (3) do activity patterns of single animals change at different population densities and according to light regime in small versus large environments? (4) does the response to predators vary with size of environment?

\section{Methods}

The experiments were conducted in oval, recirculating, laboratory stream tanks held in environmental chambers at $12^{\circ} \mathrm{C}$. The tanks were of two sizes, 43-L (length of channel on midline $=250 \mathrm{~cm}$; channel width $=14.5 \mathrm{~cm})$, described by Williams and Moore (1982), and smaller, 3.5-L (length of channel $=55$ $\mathrm{cm}$; channel width $=7.3 \mathrm{~cm}$ ). Each tank (Fig. 1) had a small plexiglass window $(2.0 \times 12.0 \mathrm{~cm})$ across the bottom of the channel on the side opposite the paddle wheel. Two curved 2$\mathrm{mm}$ mesh brass screens formed a narrow passage $1.8 \mathrm{~cm}$ wide in mid channel over the window. Two removable end screens of $1.5-\mathrm{cm}$ mesh ensured that only Gammarus could pass through this section of the tank.

Movement through this passage was monitored automatically by ultraviolet beam interruption (Wallace et al. 1975). A metal box containing the light source and holding a copper tube (1.8 $\mathrm{cm}$ diameter and $9.8 \mathrm{~cm}$ long) channeled the light into a cylindrical beam shining vertically down into the water. The copper tube was enclosed in a glass vial, to prevent direct contact with the water, and was aligned over the centre of the plexiglass window. Beneath the channel, directly under the light, a second copper tube contained an ultraviolet photocell lined up with the beam. The tube provided shading from extraneous light. Passage of animals through the beam was recorded as a line on the paper of a chart recorder operated at a speed of $3 \mathrm{~mm} / \mathrm{min}$. The electronic circuitry was specifically designed so that the amount of time spent in the beam was proportional to the length of line 


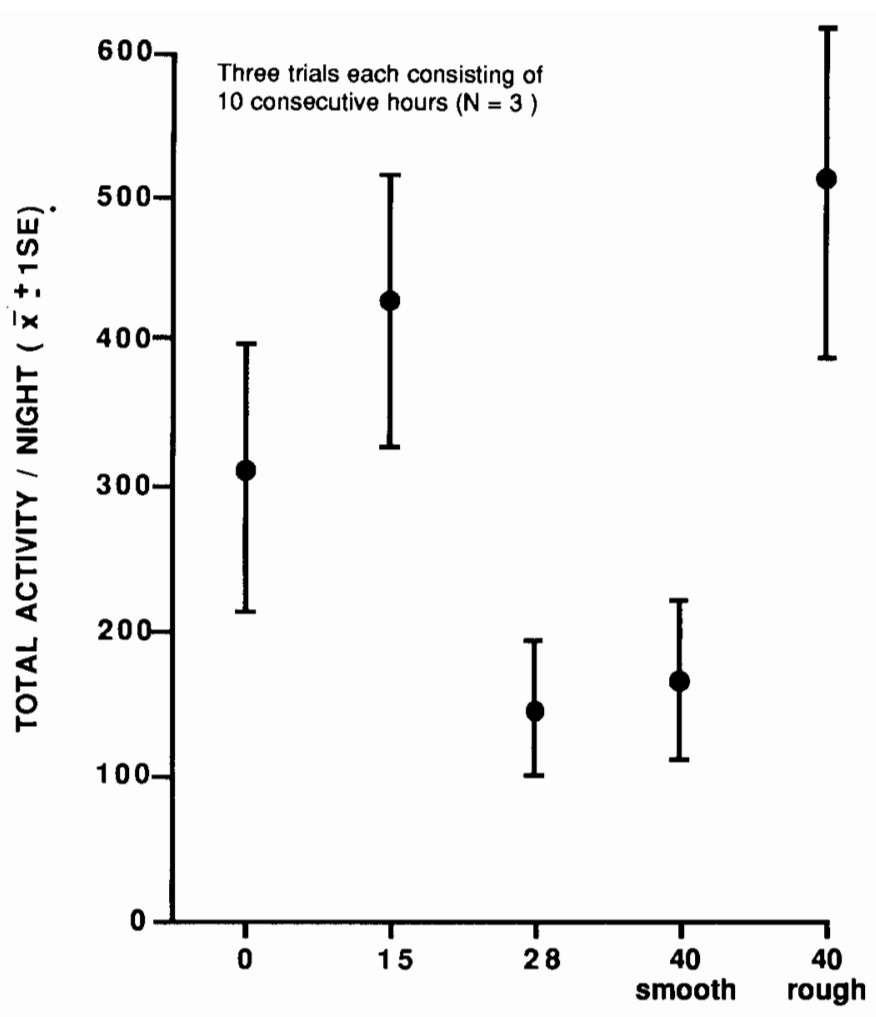

CURRENT SPEED $(\mathrm{cm} / \mathrm{s})$

FIG. 2. Total activity level (all categories combined) of 20 adult Gammarus pseudolimnaeus of mixed sexes under different current regimes (large stream tanks).

the animal finally settled, and distance of each total drift episode. These variables were measured in both the large and small tanks under standard tank conditions. In order to distinguish behavioural from physical responses, these procedures were repeated using freshly-killed amphipods. Neither live nor dead amphipods seemed to be affected when going through the passage between the two screens.

\section{Effect of Density on Activity Level}

Estimates of the activities of single amphipods at different population densities (at constant current) were calculated from the total number of activities recorded per $10-\mathrm{h}$ period divided by the appropriate number of animals in the tank. This necessitated assuming that the activity level of each animal within a single trial was similar. For these trials, the range of densities in the small tanks was from $1-40$ per tank, while in the large tanks it was 4-220. Comparisons between tank size and daynight activity were made using linear regression based on replicated values of the dependent variable $(n=10)$.

\section{Effect of Predators on Activity Level}

A number of small, similar-sized (approximately $7 \mathrm{~cm}$ long), caged dace (Rhinichthys sp.) were introduced to amphipod environments of different size (1/small tank; 5/large tank) $3 \mathrm{~h}$ after the lights went out, a time when amphipod activity was high (Williams and Moore 1982).

Statistical tests were performed on ln-transformed data in order to conform with test prerequisites of normality and homoscedasticity.

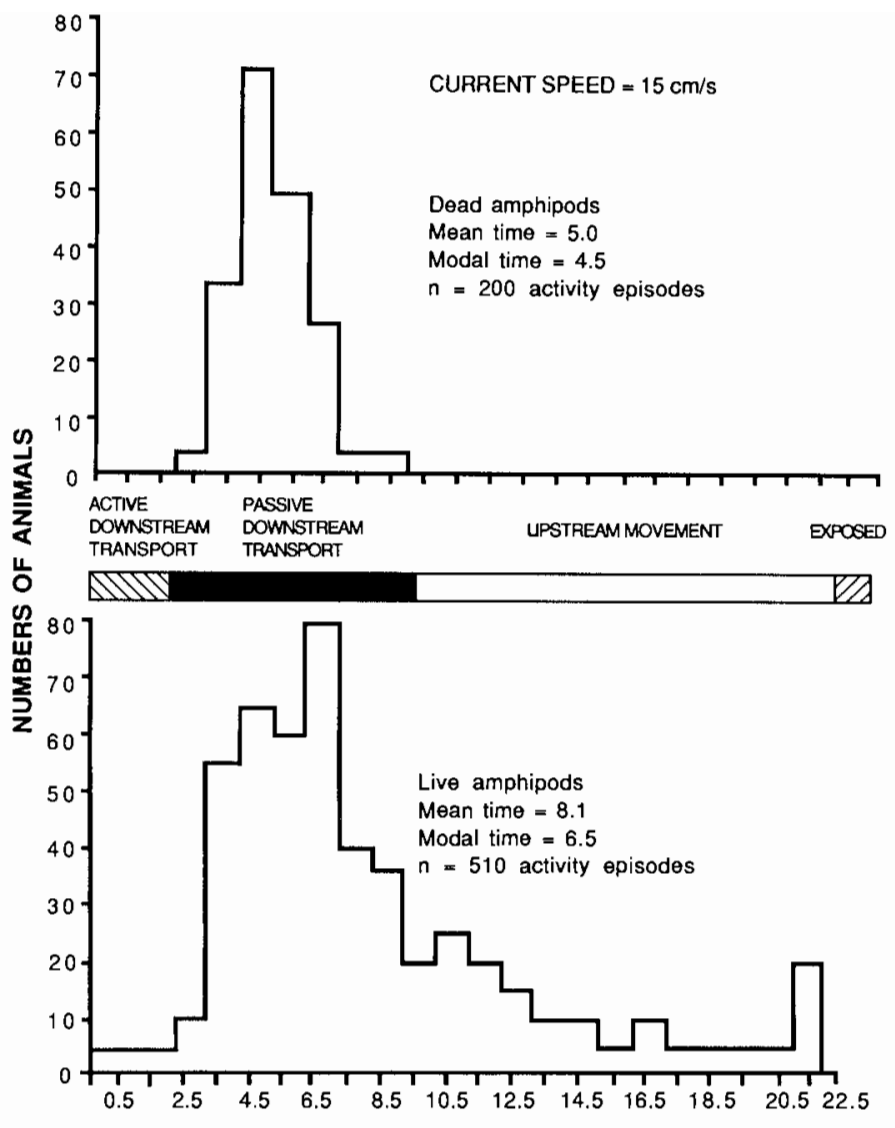

RELATIVE TIME SPÉNT CROSSING THE LIGHT BEAM

FIG. 3. Frequency distribution of the various times taken for single amphipods to pass through the light beam at a current of $15 \mathrm{~cm} / \mathrm{s}$ (large stream tanks) (Time is in relative units as passage times through the light beam were recorded as lines of various length on a chart recorder, see methods; $n=$ number of activity episodes of individual amphipods monitored which was targeted at between 200 and 550).

\section{Results}

\section{Activity Level and Type of Drift Transport at Different Currents}

Increasing current speed from $0-40 \mathrm{~cm} / \mathrm{s}$, showed a response in activity similar to that obtained by Williams and Moore (1982) over part of this range (Fig. 2). Activity was higher at zero current and at $15 \mathrm{~cm} / \mathrm{s}$ than at higher speeds, with $28 \mathrm{~cm} /$ $s$ appearing to be optimal, in the sense that this was the speed at which the animals moved least. There was a markedly significant increase $(p<0.0001, t$-test) in activity in flow that was turbulent compared with that which was smooth, even though the mean current speeds were the same. Response in terms of the type of activity also changed with current.

Details of the activity types at different current speeds are shown in Figs. 3, 4, 5, and 6. A summary of the changes of the relative proportion of each of the activity types is shown in Fig. 7. There was an increase in the proportions of animals being transported both actively and passively downstream with an increase in current from 15 to $28 \mathrm{~cm} / \mathrm{s}$, but a decrease in the proportion of animals moving upstream. Above $28 \mathrm{~cm} / \mathrm{s}$, in both smooth and rough flow conditions, upstream movement increased but the percentage exposing themselves to the current declined. The proportions of amphipods drifting also decreased at high flow. 


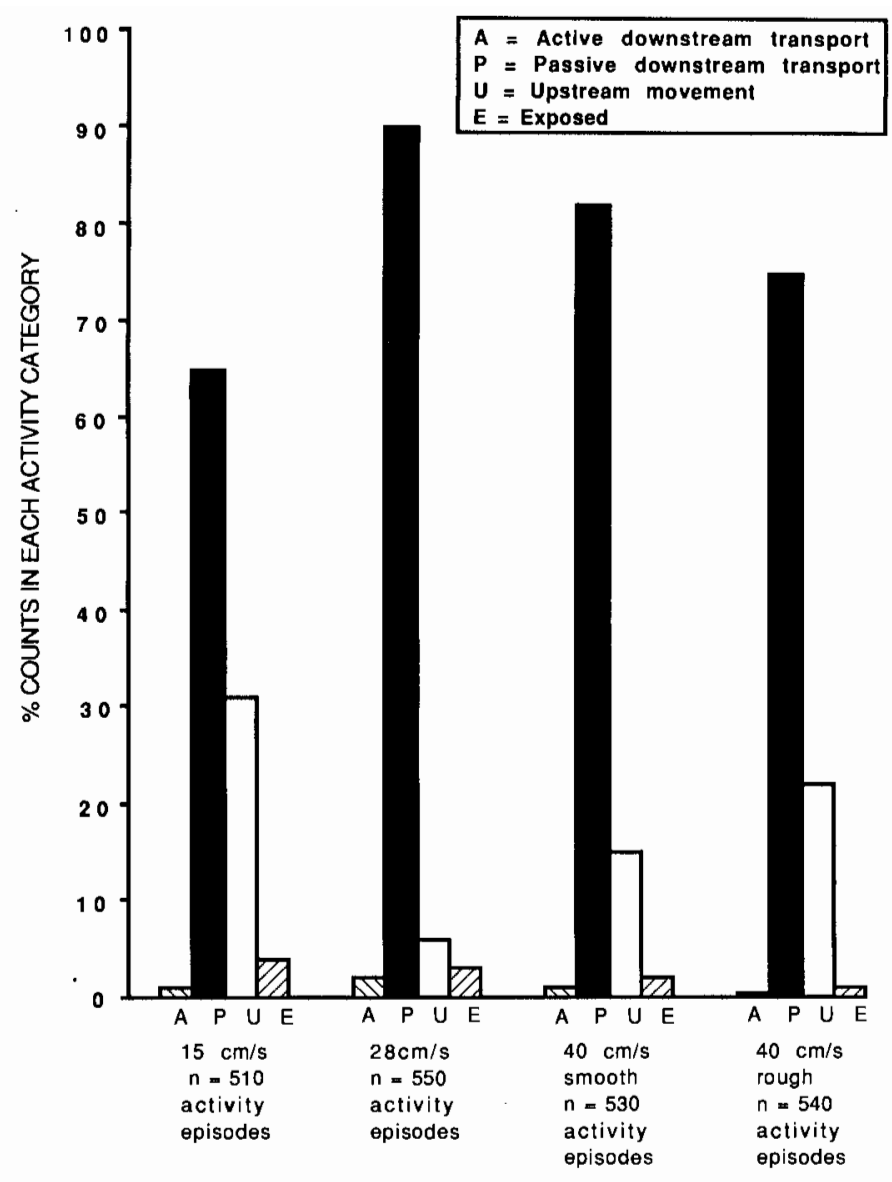

FIG. 7. Comparative summary of the changes in the relative proportions of each of the four activity types according to current regime (large stream tanks).

Total distance drifted by an animal during $12 \mathrm{~h}$ of light or darkness was estimated by dividing the total number of activity events recorded over the time period by the number of amphipods in the tank and multiplying the quotient by the linear distance around the tank. In daylight, the mean distance drifted by individual amphipods in the large tanks was 7.8 times that in the small tanks; at night it was 7.5 times greater in the large tanks. In the small tanks, individuals drifted farther $(31.4 \%$; $p<0.001, t$-test) at night than in the day and this was true also for the animals in the large tanks $(27.5 \%$ farther at night; $p<0.005, t$-test).

Another major difference between the activity patterns of the animals in the large and small tanks was the loss of the marked nocturnal peak in activity normally obtained in both the large tanks (despite equivalent animal densities) and in nature (Fig. 9).

\section{Activity of Single Amphipods at Different Densities}

Activity levels at densities from 0.002 to 0.105 animals $/ \mathrm{cm}^{2}$ of bottom substrate in the large and small tanks are shown in Table 4. Regression lines for activity versus density in the small tanks show a significant $(p<0.0001)$ positive relationship during both day and night, with a difference in line elevation but not slope (Fig. 10). Density explained some $34.3 \%$ of the variance in activity at night and $20.5 \%$ during the day.

In the large tanks, the relationship between activity and density was positive during the day but negative at night (Fig. 10).

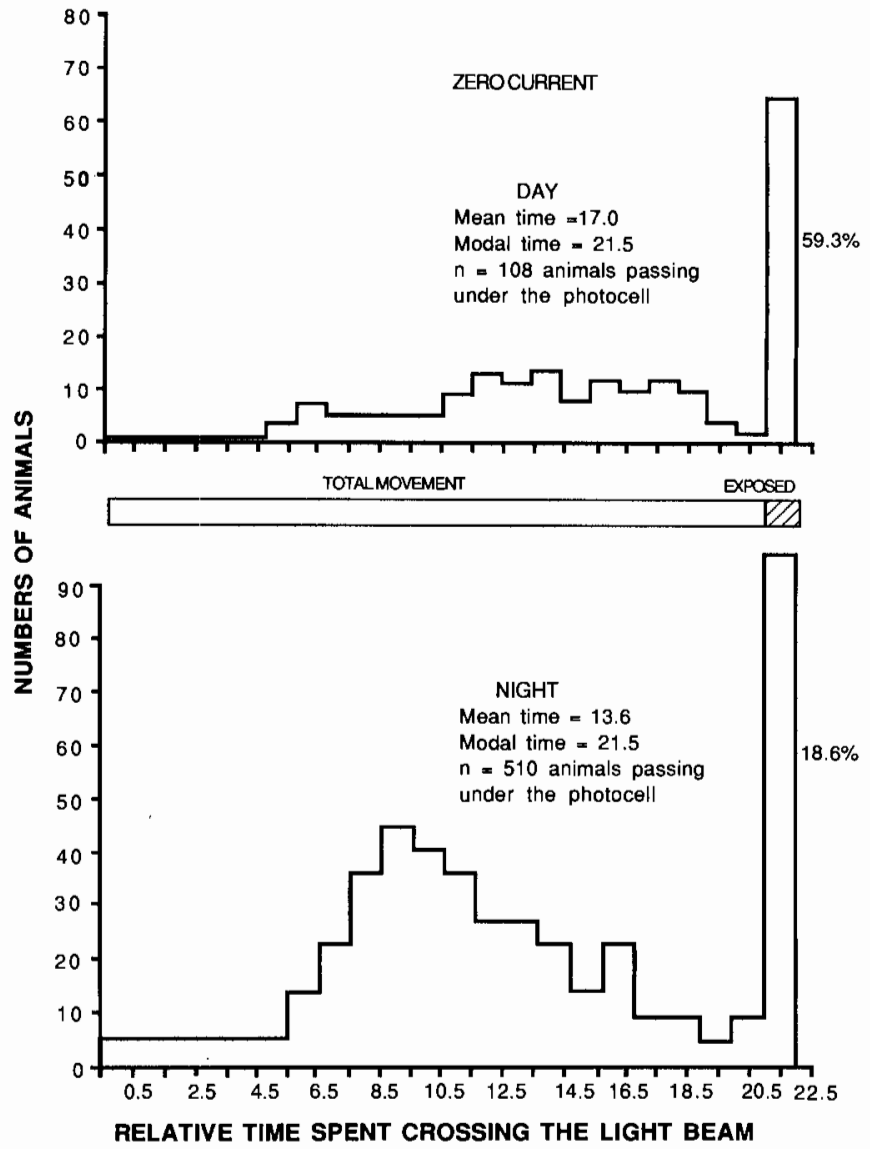

FIG. 8. Comparison between day and nighttime activity of amphipods at zero current (large stream tanks) ( $n=$ number of activity episodes of individual animals automatically timed going through the light beam).

TABLE 2. Time taken for amphipods to traverse the light beam during the day and night under standard tank conditions but different current speeds in the large stream tanks.

\begin{tabular}{lccc}
\hline \hline & \multicolumn{2}{c}{ Time taken to traverse beam ${ }^{\mathrm{a}}$} & \\
\cline { 2 - 3 } $\begin{array}{c}\text { Current } \\
(\mathrm{cm} / \mathrm{s})\end{array}$ & $\begin{array}{c}\text { Day } \\
(\bar{x} \pm 1 \mathrm{SE} ; n)\end{array}$ & $\begin{array}{c}\text { Night } \\
(\bar{x} \pm 1 \mathrm{SE} ; n)\end{array}$ & $\begin{array}{c}\text { Probability } \\
\text { (from } t \text {-test) }\end{array}$ \\
\hline 0 & $16.4 \pm 0.48(108)$ & $13.6 \pm 0.23(510)$ & $<0.001$ \\
15 & $4.1 \pm 0.15(200)$ & $8.1 \pm 0.20(510)$ & $<0.001$ \\
28 & $3.0 \pm 0.14(200)$ & $4.5 \pm 0.15(550)$ & $<0.001$ \\
40 smooth & $6.6 \pm 1.19(20)$ & $5.5 \pm 0.14(530)$ & $<0.001$ \\
40 rough & $5.7 \pm 0.54(110)$ & $5.8 \pm 0.13(540)$ & 0.5 \\
\hline
\end{tabular}

${ }^{\text {a }}$ Time is in relative units as passage times through the light beam were recorded as lines of varying length on a chart (see methods).

Both regressions were significant at $p<0.005$ although, as they only explained a small amount of the variance (14.7 and $13.2 \%$, respectively), the relationships are more probably curvilinear than linear. Linear regression, however, makes comparison of lines easier and indicates differences in both the slopes and elevations of the lines for day versus nighttime activity.

There are significant differences in the slopes $(p<0.001, F$ test) and elevations of lines ( $t$-test, $p<0.001)$ for the large and small tanks for both day and night, with activity levels in the small tanks frequently being higher than those in the large tanks despite identical densities (Table 4). 


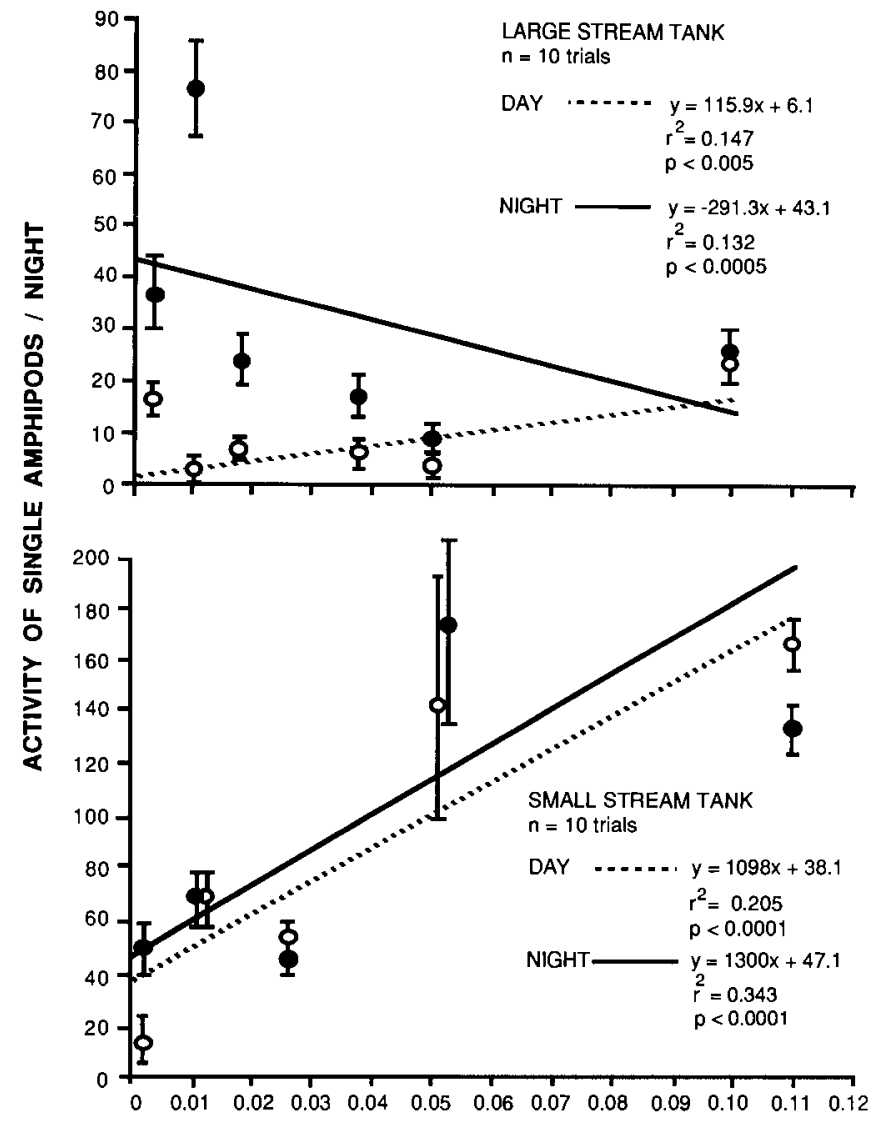

DENSITY OF AMPHIPODS $/ \mathrm{cm}^{2}$

FiG. 10. Regression lines of activity level against amphipod density in the large and small stream tanks (day and night) $(n=10 ; 10$ trials each consisting of 10 consecutive hours of day or night time activity at each density).

TABLE 5. Nocturnal activity response of Gammarus pseudolimnaeus to the presence of dace (Rhinichthys sp.) in large and small stream tanks, under standard tank conditions of substrate, depth and current.

Level of activity

(mean no. drifting/h $\pm 1 \mathrm{SE}$ ) (n)

\begin{tabular}{lccc} 
& No fish & \multicolumn{1}{c}{ Fish } & $\begin{array}{c}\text { Probability } \\
\text { (from } t \text {-test) }\end{array}$ \\
\cline { 2 - 4 } Small & $44.7 \pm 32.7(15)$ & $60.3 \pm 45.9(15)$ & $>0.5$ \\
Large & $115.0 \pm 12.2(9)$ & $50.0 \pm 7.6(9)$ & $<0.001$ \\
\hline
\end{tabular}

other environmental factors difficult to control in the field (Williams and Moore 1986).

As current speed increased to $40 \mathrm{~cm} / \mathrm{s}$, active and passive downstream transport decreased in importance while both upstream activity and overall activity levels increased substantially in the case of rough, fast current. Gammarus pseudolimnaeus can be found, in nature, in currents up to $55 \mathrm{~cm} / \mathrm{s}$ (Rees 1972) though it tends to avoid them (Marchant and Hynes 1981). The animals forced, in the laboratory, to endure high currents, hugged the substrate and showed increased positive rheotaxis, presumably to compensate for downstream transport some of which may be due to "catastrophic" displacement. Exposure to current, measured as animals sitting on the screens under the photocell, decreased linearly with increasing current $\left(y=-0.401 x+24.09 ; R^{2}=0.971 ; p<0.05\right)$. "Erodibility" of animals, and hence entry into the drift does not appear to rise automatically with increasing exposure to current (Statzner et al. 1984) although Wiley and Kohler (1984) have proposed that any behaviour that increases the probability of either exposure to eroding currents or erosion itself, substantially increases the chances of passive entry into the drift. On the other hand, G. pseudolimnaeus along with some other benthic invertebrates, such as the mayfly Baetis, seem to be in full control of their environment and do not respond to variation in current entirely as if they were inorganic particles of sediment (Campbell 1985).

Our data revealed important diel differences in amphipod activity between darkness and light. A nocturnal peak in the frequency of activity of Gammarus is well documented both in the field and laboratory (e.g. Waters 1962; Wallace et al. 1975). However, the significant differences in swimming speed of individuals between day and night is intriguing. Faster swimming in the daytime (at 15 and $28 \mathrm{~cm} / \mathrm{s}$ ) might be interpreted as minimizing exposure to visual predators but why should this pattern be reversed at $40 \mathrm{~cm} / \mathrm{s}$ (smooth flow) and at zero current? Lack of any diel difference in swimming speed at $40 \mathrm{~cm} / \mathrm{s}$ (rough flow) could perhaps indicate steady, uniform swimming in an attempt to escape a totally unacceptable current regime - recall that this condition resulted in maximum overall activity levels.

In both sizes of stream tank, individual amphipods drifted significantly farther (27-31\%) at night than during the day. Elliott (1971) found no difference between day and night but found that distance drifted was related to species, current, and substrate type. The greater nocturnal drift distances recorded for Baetis by Statzner and Mogel (1985) were thought to be the result of disorientation of the nymphs at the loss of a dorsal light stimulus. Total distances drifted by individual G. pseudolimnaeus in a single drift episode differed significantly between small and large stream tanks ( $\bar{x}=0.45$ and $0.59 \mathrm{~m}$, respectively at night). Both estimates fall short of the fieldmeasured range reported for Gammarus (e.g. $\bar{x}=1.0$ to $5.7 \mathrm{~m}$ G. pulex (L.); Elliott (1971) and $\bar{x}=28.5 \mathrm{~m} \mathrm{G}$. pseudolimnaeus; McLay (1970)). In our small stream tanks, individual animals underwent an average of 6.8 drift episodes (Table 3) during $12 \mathrm{~h}$ of darkness for a total mean nightly downstream displacement of $3.04 \mathrm{~m}$. Individuals in the large stream tanks underwent an average of 37.9 episodes during which they covered a mean total distance of $22.37 \mathrm{~m}$. Mean distances drifted by invertebrates in a disturbance experiment in streams in British Columbia ranged from 0.58 to $13.85 \mathrm{~m}$ (Larkin and McKone 1985) and distances drifted by three species of mayfly in a combined model/field study in Alberta ranged from 6.43 to $14.98 \mathrm{~m}$ (Ciborowski 1987). Thus although our individual drift episode distances are low compared with other studies, our estimates of total nightly displacement are closer. Field studies have not shown whether individual animals undergo multiple nocturnal drift episodes. The fact that dead animals touched the walls or substrate significantly more often in the small stream tanks whereas the rate of touching by live animals was the same between tanks strongly suggests a behavioural response. Thus G. Pseudolimnaeus may test the substrate at regular intervals while drifting. This process appears to be independent of local environment scale.

Variance around the mean values of the drift parameters shown in Table 3 is generally low indicating considerable similarity in drift behaviour between individual animals which, perhaps, points to a more structured (in terms of time and/or distance) format to the drift process than has been thought in 
the past. The larger variances associated with distances drifted in some previous studies may be due to the manner of creation of drift events. For example, quite a number of studies have generated drift by mechanically disturbing the benthos. Presumably there is a difference in the determination/ability of artificially-displaced individuals (compared with behavioural (= voluntary) drifters) to return to the substrate and this will affect the distance drifted. The position in the water column to which animals are relegated by disturbance also may affect the latter as, e.g. a particular species normally may drift close to the substrate but be displaced higher by experimental disturbance. An alternative explanation for the lower variance in our drift data is that, in the field, estimates include animals drifting from a number of upstream microhabitats thus the physiological or behavioural states of the animals may be more varied.

Relationships between drift densities and benthic densities have been sought, frequently, with limited success (Waters 1972; Brittain and Eikeland 1988). In one instance where density dependence was demonstrated (in the stonefly Taeniopte$r y x$ ), the relationship broke down at current velocities less than $25 \mathrm{~cm} / \mathrm{s}$ (Walton 1980). On occasion, drift of one larval group appears to be more related to the benthic densities of other larval groups than to their own (Statzner et al. 1987). No relationships have been shown between drift of various species of Gammarus and their own benthic densities in either field or laboratory studies (Statzner et al. 1984). Our data show a positive relationship between level of drift activity and benthic density of $G$. pseudolimnaeus, during both day and night, in the small stream tanks although the relationship possibly becomes asymptotic at high benthic densities (Fig. 10). In the large stream tanks the daytime relationship was different from that seen at night. Negative correlations, such as seen at night, have been documented for some southern Australian upland stream species (Graesser and Lake 1984).

It is known that drift rate in $G$. pseudolimnaeus varies according to microenvironmental features such as substrate size, current speed, and the presence of other members of the benthic community (Williams and Moore 1982, 1985, Fig. 11) and this has been shown for other benthic species as well (Waiton et al. 1977, Williams 1986). The major difference in environmental conditions between our large and small stream tanks was one of scale. These and other differences in the various drift parameters measured between the two sizes of tank together with the loss of marked nocturnal activity in the small tanks and the differential response to predators between tanks may reflect differences in perception of local environmental scale by the amphipods. An evaluation of the streambed may be made during the periodic contacts that $G$. pseudolimnaeus makes with the substrate during the transport phase of a drift episode.

It might be argued that small stream tanks, while allowing accurate estimation of benthic densities and registering of individual drift activity, represent somewhat more artificial environments than larger versions, and thus some observed differences may be due to behavioural artifacts (Statzner et al. 1984). There does not appear, however, to be any proof to support this in the literature. Moreover, drift density is typically less in small versus large rivers (Armitage 1977; Ciborowski 1987).

Our data support the recent hypothesis of Ciborowski (1987) that "the dimensions of small streams may be such that freeranging individuals could sample the entire range of microhabits available solely through relatively short-scale benthic movements"'. Although Ciborowski's (1987) proposal applied to the characteristics of populations that had been selected for, rather than to plasticity on the part of genetically similar individuals, our data suggest that it may be applicable to the latter as well. Thus, in our small stream tanks, the volume/area of local environment may have been sufficiently small so as to enable individual amphipods to retain some form of awareness of, or familiarity with, its properties. Perhaps having perceived a "safe", though finite, environment the animals abandoned the need to be primarily night active resulting in the loss of the typical diel activity pattern. Further, even in the presence of the odour of a predator, after failing to encounter a real (or more tangible) threat within their " known" environment, they either ignore or habituate to the stimulus. An alternative, though related, explanation could be that, in the small tanks, individual amphipods contact the walls of the tanks more frequently than in the larger tanks (Table 3). As the tank walls probably register as vertical rock faces, the animals' overall perception of their own status in the small tanks may be one of being in the interstices between large rocks in a complex, "safe" (= predator free) environment. This results in reduced activity (Williams and Moore 1982) and loss of response of predators. We do not mean to imply here a level of consciousness above that normally attributed to invertebrate animals but rather behavioural changes resulting from optimal responses to particular environmental stimuli.

In this study we have provided evidence of the complexity of the drifting process in running water. We conclude by combining these results with those of our previous work on G. pseudolimnaeus to emphasize this complexity (Fig. 11). Clearly, this species is more active in some environments than in others. However, even within a single environment, various biotic and abiotic factors act independently or interactively to control the qualitative and quantitative nature of both drift and upstream movements. The details of these relationships, shown in Fig. 11 , are largely self explanatory.

\section{Acknowledgements}

We thank the Natural Sciences and Engineering Research Council of Canada for funding the project. N. J. Olyslager drew Fig. 11.

\section{References}

andersson, K. G., C. Bronmark, J. Herrmann, B. Malmevist, C. Otto, AND P. SJOSTROM. 1986. Presence of sculpins (Cottus gobio) reduces drift and activity of Gammarus pulex (Amphipoda). Hydrobiologia 133: 209215 .

ARMitaGe, P. D. 1977. Invertebrate drift in the regulated River Tees, and an unregulated tributary, Maize Beck, below Cow Green dam. Freshwater Biol. 7: 167-184.

BISHOP, J. E., AND H. B. N. HyNes. 1969. Upstream movements of the benthic invertebrates in the Speed River, Ontario, Canada. J. Fish. Res. Board Can. 26: 279-298.

Brittain, J. E., AND T. J. Eikeland. 1988. Invertebrate drift - a review. Hydrobiologia 166: 77-93.

CAMPBell, R. N. B. 1985. Comparison of live and dead Baetis nymphs in a weakening water current. Hydrobiologia 126: 229-236.

Cligorowski, J. J. H. 1987. Dynamics of drift and microdistribution of two mayfly populations: a predictive model. Can. J. Fish. Aquat. Sci. 44: 832845.

Corkum, L. D., P. J. Pointing, and J. J. H. Ciborowski. 1977. The influence of current velocity and substrate on the distribution and drift of two species of mayflies (Ephemeroptera). Can. J. Zool. 55: 1970-1977.

CuLP, J. M. 1986. Experimental evidence that stream macroinvertebrate community structure is unaffected by different densities of coho salmon fry. J. N. Am. Benthol. Soc. 5: 140-149.

ELLIOTT, J. M. 1971. The distances travelled by drifting invertebrates in a Lake District stream. Oecologia 6: 350-379. 


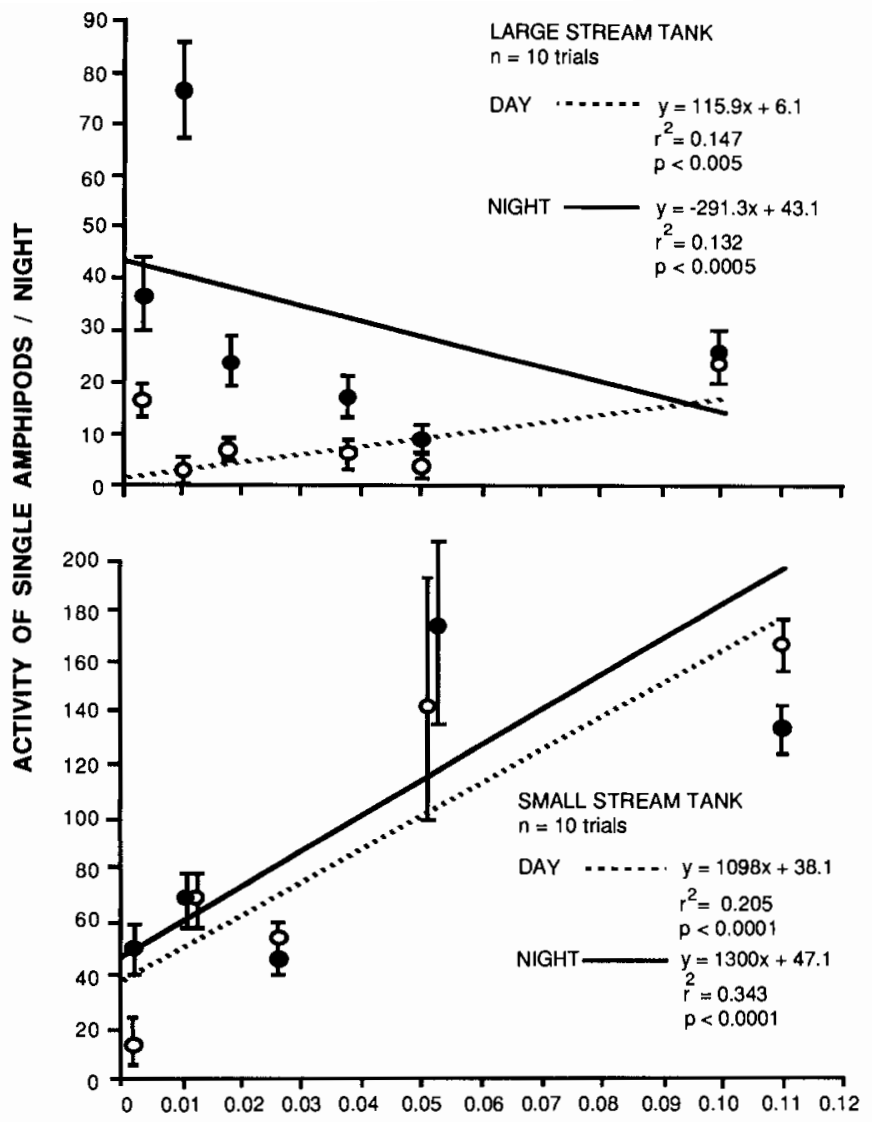

DENSITY OF AMPHIPODS $/ \mathrm{cm}^{2}$

F1G. 10. Regression lines of activity level against amphipod density in the large and small stream tanks (day and night) $(n=10 ; 10$ trials each consisting of 10 consecutive hours of day or night time activity at each density).

TABLE 5. Nocturnal activity response of Gammarus pseudolimnaeus to the presence of dace (Rhinichthys sp.) in large and small stream tanks, under standard tank conditions of substrate, depth and current.

Level of activity

(mean no. drifting/h $\pm 1 \mathrm{SE}$ ) (n)

\begin{tabular}{lccc} 
& Nank size & \multicolumn{1}{c}{ Fish } & $\begin{array}{c}\text { Probability } \\
\text { (from } t \text {-test) }\end{array}$ \\
\cline { 2 - 3 } Small & $44.7 \pm 32.7(15)$ & $60.3 \pm 45.9(15)$ & $>0.5$ \\
Large & $115.0 \pm 12.2(9)$ & $50.0 \pm 7.6(9)$ & $<0.001$ \\
\hline
\end{tabular}

other environmental factors difficult to control in the field (Williams and Moore 1986).

As current speed increased to $40 \mathrm{~cm} / \mathrm{s}$, active and passive downstream transport decreased in importance while both upstream activity and overall activity levels increased substantially in the case of rough, fast current. Gammarus pseudolimnaeus can be found, in nature, in currents up to $55 \mathrm{~cm} / \mathrm{s}$ (Rees 1972) though it tends to avoid them (Marchant and Hynes 1981). The animals forced, in the laboratory, to endure high currents, hugged the substrate and showed increased positive rheotaxis, presumably to compensate for downstream transport some of which may be due to "catastrophic" displacement. Exposure to current, measured as animals sitting on the screens under the photocell, decreased linearly with increasing current $\left(y=-0.401 x+24.09 ; R^{2}=0.971 ; p<0.05\right)$. "Erodibility" of animals, and hence entry into the drift does not appear to rise automatically with increasing exposure to current (Statzner et al. 1984) although Wiley and Kohler (1984) have proposed that any behaviour that increases the probability of either exposure to eroding currents or erosion itself, substantially increases the chances of passive entry into the drift. On the other hand, G. pseudolimnaeus along with some other benthic invertebrates, such as the mayfly Baetis, seem to be in full control of their environment and do not respond to variation in current entirely as if they were inorganic particles of sediment (Campbell 1985).

Our data revealed important diel differences in amphipod activity between darkness and light. A nocturnal peak in the frequency of activity of Gammarus is well documented both in the field and laboratory (e.g. Waters 1962; Wallace et al. 1975). However, the significant differences in swimming speed of individuals between day and night is intriguing. Faster swimming in the daytime (at 15 and $28 \mathrm{~cm} / \mathrm{s}$ ) might be interpreted as minimizing exposure to visual predators but why should this pattern be reversed at $40 \mathrm{~cm} / \mathrm{s}$ (smooth flow) and at zero current? Lack of any diel difference in swimming speed at $40 \mathrm{~cm} / \mathrm{s}$ (rough flow) could perhaps indicate steady, uniform swimming in an attempt to escape a totally unacceptable current regime - recall that this condition resulted in maximum overall activity levels.

In both sizes of stream tank, individual amphipods drifted significantly farther $(27-31 \%)$ at night than during the day. Elliott (1971) found no difference between day and night but found that distance drifted was related to species, current, and substrate type. The greater nocturnal drift distances recorded for Baetis by Statzner and Mogel (1985) were thought to be the result of disorientation of the nymphs at the loss of a dorsal light stimulus. Total distances drifted by individual G. pseudolimnaeus in a single drift episode differed significantly between small and large stream tanks $(\bar{x}=0.45$ and $0.59 \mathrm{~m}$, respectively at night). Both estimates fall short of the fieldmeasured range reported for Gammarus (e.g. $\bar{x}=1.0$ to $5.7 \mathrm{~m}$ G. pulex (L.); Elliott (1971) and $\bar{x}=28.5 \mathrm{~m} \mathrm{G}$. pseudolimnaeus; McLay (1970)). In our small stream tanks, individual animals underwent an average of $6.8 \mathrm{drift}$ episodes (Table 3 ) during $12 \mathrm{~h}$ of darkness for a total mean nightly downstream displacement of $3.04 \mathrm{~m}$. Individuals in the large stream tanks underwent an average of 37.9 episodes during which they covered a mean total distance of $22.37 \mathrm{~m}$. Mean distances drifted by invertebrates in a disturbance experiment in streams in British Columbia ranged from 0.58 to $13.85 \mathrm{~m}$ (Larkin and McKone 1985) and distances drifted by three species of mayfly in a combined model/field study in Alberta ranged from 6.43 to $14.98 \mathrm{~m}$ (Ciborowski 1987). Thus although our individual drift episode distances are low compared with other studies, our estimates of total nightly displacement are closer. Field studies have not shown whether individual animals undergo multiple nocturnal drift episodes. The fact that dead animals touched the walls or substrate significantly more often in the small stream tanks whereas the rate of touching by live animals was the same between tanks strongly suggests a behavioural response. Thus G. Pseudolimnaeus may test the substrate at regular intervals while drifting. This process appears to be independent of local environment scale.

Variance around the mean values of the drift parameters shown in Table 3 is generally low indicating considerable similarity in drift behaviour between individual animals which, perhaps, points to a more structured (in terms of time and/or distance) format to the drift process than has been thought in 
the past. The larger variances associated with distances drifted in some previous studies may be due to the manner of creation of drift events. For example, quite a number of studies have generated drift by mechanically disturbing the benthos. Presumably there is a difference in the determination/ability of artificially-displaced individuals (compared with behavioural $(=$ voluntary) drifters) to return to the substrate and this will affect the distance drifted. The position in the water column to which animals are relegated by disturbance also may affect the latter as, e.g. a particular species normally may drift close to the substrate but be displaced higher by experimental disturbance. An alternative explanation for the lower variance in our drift data is that, in the field, estimates include animals drifting from a number of upstream microhabitats thus the physiological or behavioural states of the animals may be more varied.

Relationships between drift densities and benthic densities have been sought, frequently, with limited success (Waters 1972; Brittain and Eikeland 1988). In one instance where density dependence was demonstrated (in the stonefly Taeniopte$r y x)$, the relationship broke down at current velocities less than $25 \mathrm{~cm} / \mathrm{s}$ (Walton 1980). On occasion, drift of one larval group appears to be more related to the benthic densities of other larval groups than to their own (Statzner et al. 1987). No relationships have been shown between drift of various species of Gammarus and their own benthic densities in either field or laboratory studies (Statzner et al. 1984). Our data show a positive relationship between level of drift activity and benthic density of $G$. pseudolimnaeus, during both day and night, in the small stream tanks although the relationship possibly becomes asymptotic at high benthic densities (Fig. 10). In the large stream tanks the daytime relationship was different from that seen at night. Negative correlations, such as seen at night, have been documented for some southern Australian upland stream species (Graesser and Lake 1984).

It is known that drift rate in $G$. pseudolimnaeus varies according to microenvironmental features such as substrate size, current speed, and the presence of other members of the benthic community (Williams and Moore 1982, 1985, Fig. 11) and this has been shown for other benthic species as well (Walton et al. 1977, Williams 1986). The major difference in environmental conditions between our large and small stream tanks was one of scale. These and other differences in the various drift parameters measured between the two sizes of tank together with the loss of marked nocturnal activity in the small tanks and the differential response to predators between tanks may reflect differences in perception of local environmental scale by the amphipods. An evaluation of the streambed may be made during the periodic contacts that G. pseudolimnaeus makes with the substrate during the transport phase of a drift episode.

It might be argued that small stream tanks, while allowing accurate estimation of benthic densities and registering of individual drift activity, represent somewhat more artificial environments than larger versions, and thus some observed differences may be due to behavioural artifacts (Statzner et al. 1984). There does not appear, however, to be any proof to support this in the literature. Moreover, drift density is typically less in small versus large rivers (Armitage 1977; Ciborowski 1987).

Our data support the recent hypothesis of Ciborowski (1987) that "the dimensions of small streams may be such that freeranging individuals could sample the entire range of microhabits available solely through relatively short-scale benthic movements". Although Ciborowski's (1987) proposal applied to the characteristics of populations that had been selected for, rather than to plasticity on the part of genetically similar individuals, our data suggest that it may be applicable to the latter as well. Thus, in our small stream tanks, the volume/area of local environment may have been sufficiently small so as to enable individual amphipods to retain some form of awareness of, or familiarity with, its properties. Perhaps having perceived a "safe", though finite, environment the animals abandoned the need to be primarily night active resulting in the loss of the typical diel activity pattern. Further, even in the presence of the odour of a predator, after failing to encounter a real (or more tangible) threat within their "known" environment, they either ignore or habituate to the stimulus. An alternative, though related, explanation could be that, in the small tanks, individual amphipods contact the walls of the tanks more frequently than in the larger tanks (Table 3). As the tank walls probably register as vertical rock faces, the animals' overall perception of their own status in the small tanks may be one of being in the interstices between large rocks in a complex, "safe" (= predator free) environment. This results in reduced activity (Williams and Moore 1982) and loss of response of predators. We do not mean to imply here a level of consciousness above that normally attributed to invertebrate animals but rather behavioural changes resulting from optimal responses to particular environmental stimuli.

In this study we have provided evidence of the complexity of the drifting process in running water. We conclude by combining these results with those of our previous work on G. pseudolimnaeus to emphasize this complexity (Fig. 11). Clearly, this species is more active in some environments than in others. However, even within a single environment, various biotic and abiotic factors act independently or interactively to control the qualitative and quantitative nature of both drift and upstream movements. The details of these relationships, shown in Fig. 11 , are largely self explanatory.

\section{Acknowledgements}

We thank the Natural Sciences and Engineering Research Council of Canada for funding the project. N. J. Olyslager drew Fig. 11.

\section{References}

Andersson, K. G., C. Bronmark, J. Herrmann, B. Malmqvist, C. Otto, AND P. SJOSTROM. 1986. Presence of sculpins (Cottus gobio) reduces drift and activity of Gammarus pulex (Amphipoda). Hydrobiologia 133: 209215.

ARMITAGE, P. D. 1977. Invertebrate drift in the regulated River Tees, and an unregulated tributary, Maize Beck, below Cow Green dam. Freshwater Biol. 7: 167-184.

BISHOP, J. E., AND H. B. N. HYNES. 1969. Upstream movements of the benthic invertebrates in the Speed River, Ontario, Canada. J. Fish. Res. Board Can. 26: 279-298.

Brittain, J. E., AND T. J. Eikeland. 1988. Invertebrate drift - a review. Hydrobiologia 166: 77-93.

CAmpbell, R. N. B. 1985. Comparison of live and dead Baetis nymphs in a weakening water current. Hydrobiologia 126: 229-236.

Ciborowski, J. J. H. 1987. Dynamics of drift and microdistribution of two mayfly populations: a predictive model. Can. J. Fish. Aquat. Sci. 44: 832845 .

Corkum, L. D., P. J. Pointing, and J. J. H. Ciborowski. 1977. The influence of current velocity and substrate on the distribution and drift of two species of mayflies (Ephemeroptera). Can. J. Zool. 55: 1970-1977.

CulP, J. M. 1986. Experimental evidence that stream macroinvertebrate community structure is unaffected by different densities of coho salmon fry. J. N. Am. Benthol. Soc. 5: 140-149.

ELLIOTT, J. M. 1971. The distances travelled by drifting invertebrates in a Lake District stream. Oecologia 6: 350-379. 
TABLE 3. Measured differences in drift parameters between large (43-L) and small (3.5-L) stream tanks under standard tank conditions of 11.0$\mathrm{mm}$ diameter substrate, $13-\mathrm{cm}$ depth of water, current of $15 \mathrm{~cm} / \mathrm{s}$ and density ( 20 animals/large tank, 4 animals/small tank).

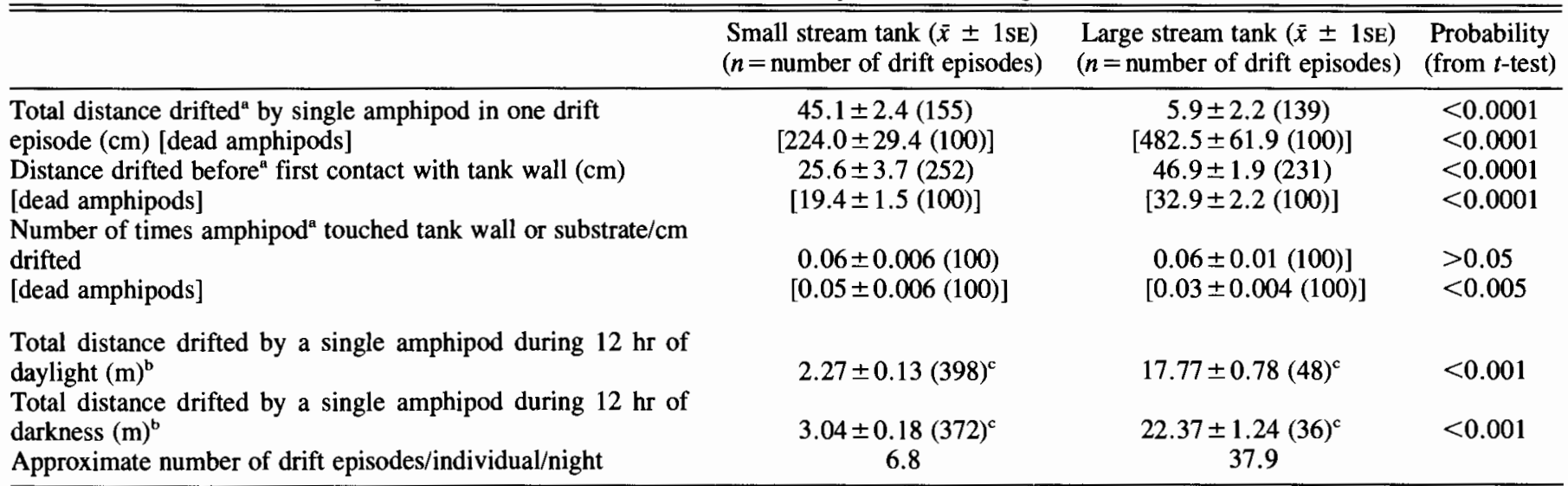

${ }^{\text {a}}$ Based on direct observations during daylight.

'Estimated by dividing the total number of activity events recorded by the photocell over the time period by the number of amphipods in the tank and multiplying the product by the linear distance around the tank.

'Differences between these pairs significant at $p<0.05$.

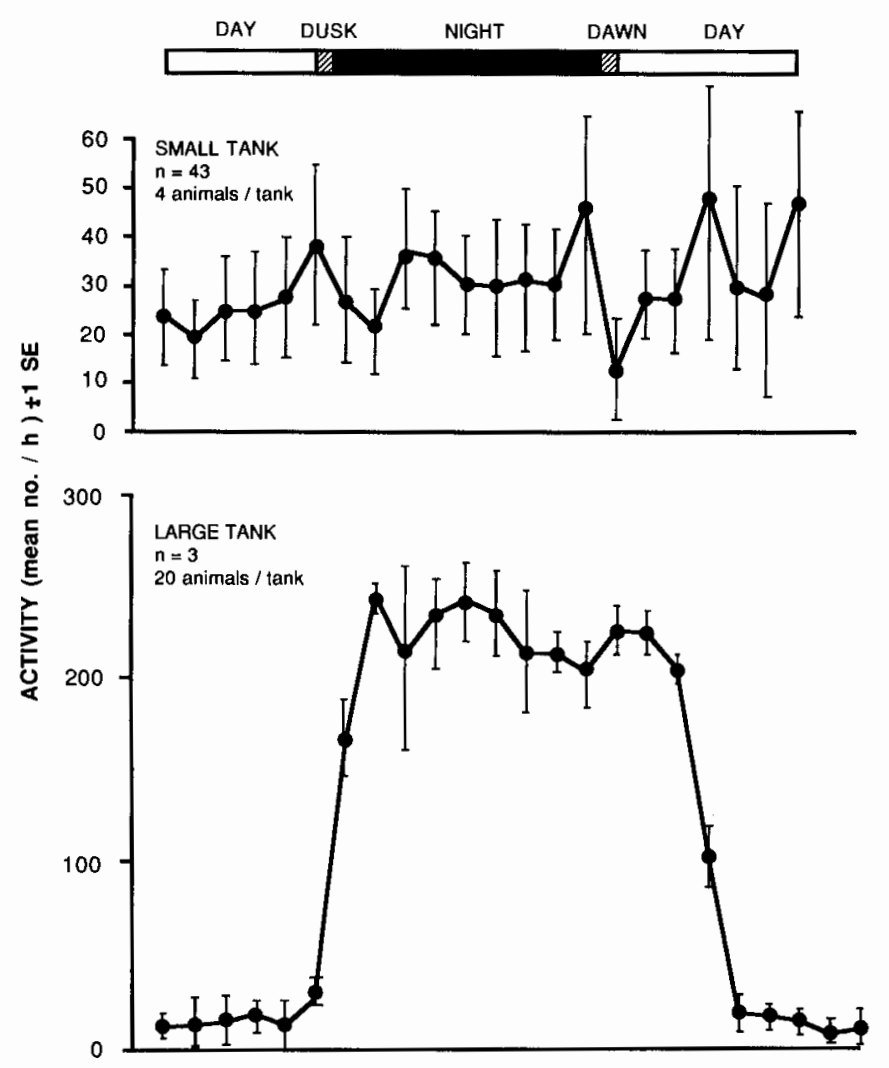

TIME

Fig. 9. Difference between diel activity patterns of amphipods in the small and large stream tanks ( $n=$ number of trials with fresh animals).

\section{Response to Predators in Environments of Different Size}

Addition of predaceous, lotic species of dace (Rhinichthys sp.) to the large stream tanks produced, within minutes, a significant drop in amphipod activity level $(p<0.001, t$-test; Table 5). However, this did not occur in the small stream tanks. In both sizes of tank each animal drifted several times per hour.
TABLE 4. Summary of the nocturnal activity levels of single amphipods at different densities in large (43-L) and small (3.5-L) stream tanks under standard tank conditions of substrate, depth and current.

\begin{tabular}{|c|c|c|c|}
\hline \multirow[b]{2}{*}{ Density $/ \mathrm{cm}^{2}$} & \multirow[b]{2}{*}{ Period } & \multicolumn{2}{|c|}{ Activity $/ 10 \mathrm{~h}( \pm 1 \mathrm{SE} ; n=10)$} \\
\hline & & $\begin{array}{l}\text { Small stream tank } \\
\text { (density/tank) }\end{array}$ & $\begin{array}{l}\text { Large stream tank } \\
\text { (density/tank) }\end{array}$ \\
\hline 0.002 & $\begin{array}{l}\text { Day } \\
\text { night }\end{array}$ & $\begin{array}{l}17.4 \pm 7.6(1) \\
49.5 \pm 10.6(1)\end{array}$ & $\begin{array}{l}18.5 \pm 3.6(4) \\
37.1 \pm 7.2(4)\end{array}$ \\
\hline 0.010 & $\begin{array}{l}\text { Day } \\
\text { night }\end{array}$ & $\begin{array}{l}59.1 \pm 11.5(4) \\
59.1 \pm 8.6(4)\end{array}$ & $\begin{array}{r}3.5 \pm 1.3(20) \\
77.3 \pm 9.9(20)\end{array}$ \\
\hline 0.019 & $\begin{array}{l}\text { Day } \\
\text { night }\end{array}$ & & $\begin{array}{r}7.0 \pm 1.6(40) \\
25.7 \pm 4.9(40)\end{array}$ \\
\hline 0.026 & $\begin{array}{l}\text { Day } \\
\text { night }\end{array}$ & $\begin{array}{l}56.8 \pm 5.7(10) \\
45.7 \pm 4.2(10)\end{array}$ & \\
\hline 0.039 & $\begin{array}{l}\text { Day } \\
\text { night }\end{array}$ & & $\begin{array}{r}5.6 \pm 1.7(80) \\
17.3 \pm 2.0(80)\end{array}$ \\
\hline 0.053 & $\begin{array}{l}\text { Day } \\
\text { night }\end{array}$ & $\begin{array}{l}140.1 \pm 54.3(20) \\
174.1 \pm 40.5(20)\end{array}$ & $\begin{array}{l}4.1 \pm 1.2(100) \\
8.7 \pm 1.8(100)\end{array}$ \\
\hline 0.105 & $\begin{array}{l}\text { Day } \\
\text { night }\end{array}$ & $\begin{array}{l}132.8 \pm 7.2(40) \\
163.8 \pm 6.7(40)\end{array}$ & $\begin{array}{l}24.6 \pm 3.0(225) \\
26.1 \pm 3.19(225)\end{array}$ \\
\hline
\end{tabular}

\section{Discussion}

Our designated categories of drift refer primarily to what is generally accepted to fall under the definition of "behavioural drift''. The data may, nevertheless, contain some low-level component of "constant drift" as the latter is difficult to single out. Active and passive downstream transport were maximal, and upstream activity was minimal, at $28 \mathrm{~cm} / \mathrm{s}$. However, the overall level of activity at this speed was the lowest of any of the current regimes, agreeing with our prior finding that, in the laboratory, optimum current conditions for this species appear to be around $25 \mathrm{~cm} / \mathrm{s}$ (Williams and Moore 1982). We assume that organisms move around less in conditions that they prefer but are more active in less suitable surroundings, the result of simple kinetic or taxic responses (Williams 1986). In the field, in contrast, $G$. pseudolimnaeus preferentially colonized microhabits exhibiting close to zero current rather than those in the range of $15-25 \mathrm{~cm} / \mathrm{s}$; this result may have been influenced by 


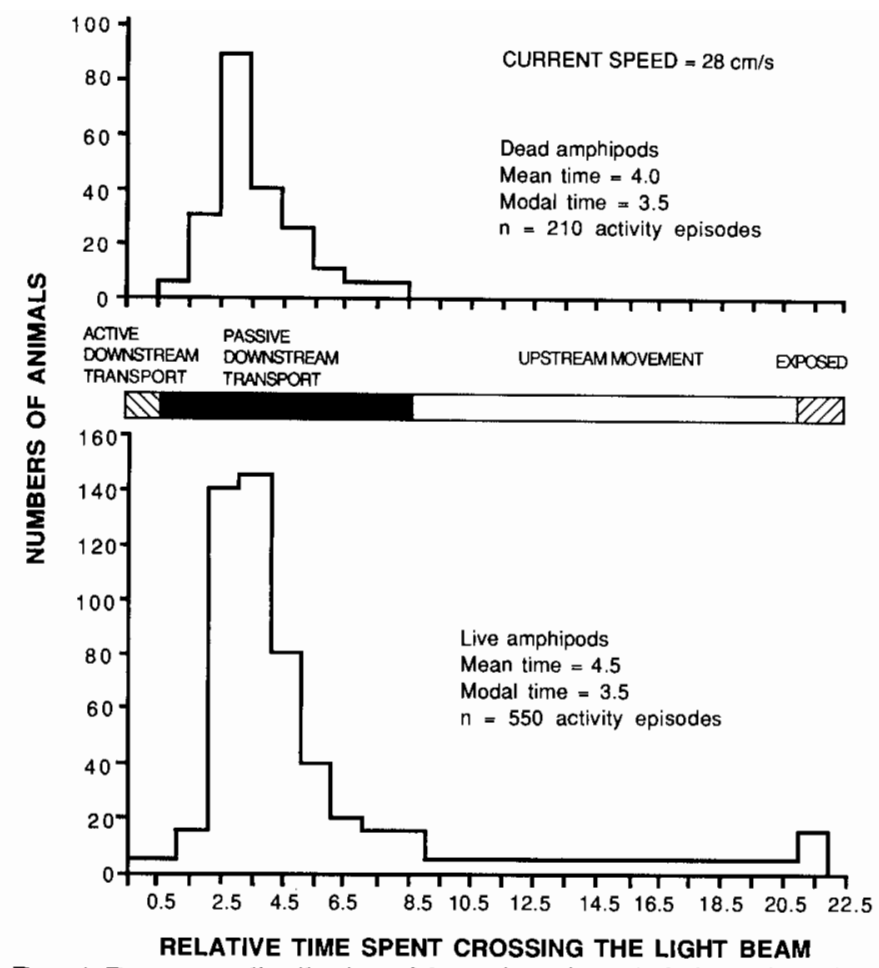

FIG. 4. Frequency distribution of the various times (relative units) taken for single amphipods to pass through the light beam at a current of 28 $\mathrm{cm} / \mathrm{s}$ (large stream tanks).

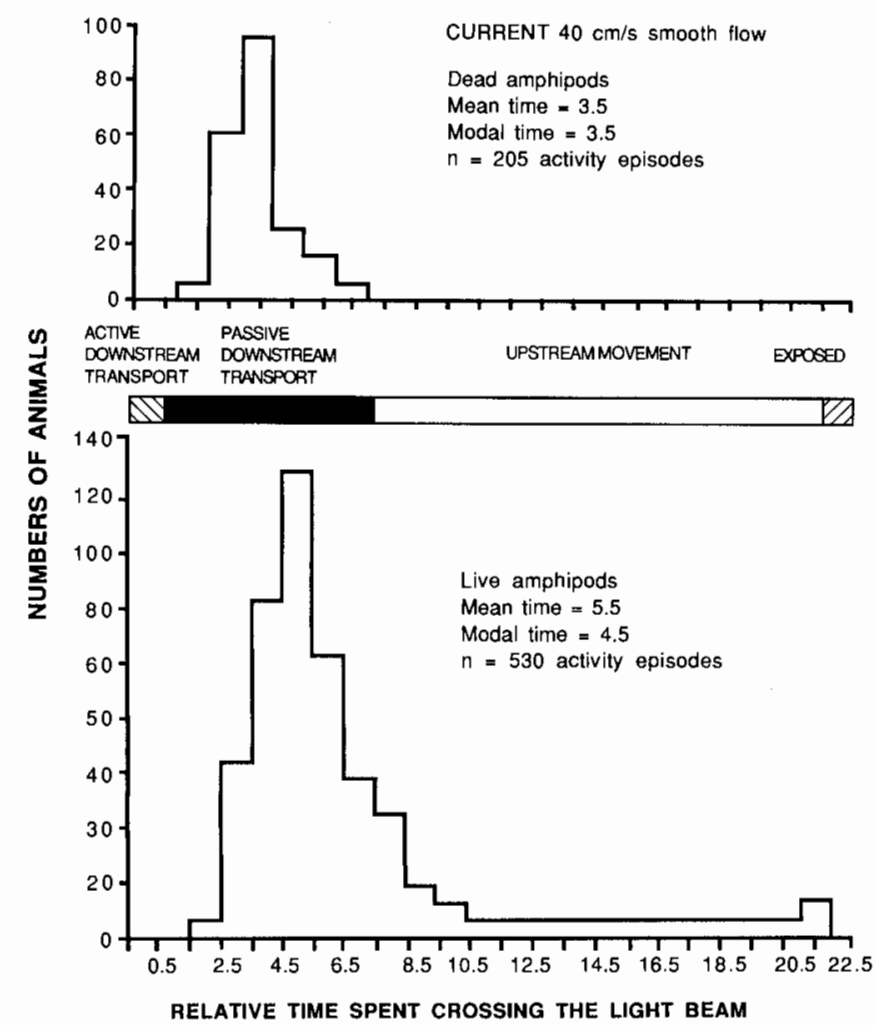

FIG. 5. Frequency distribution of the various times (relative units) taken for single amphipods to pass through the light beam at a current of 40 $\mathrm{cm} / \mathrm{s}$ (smooth flow; large stream tanks).

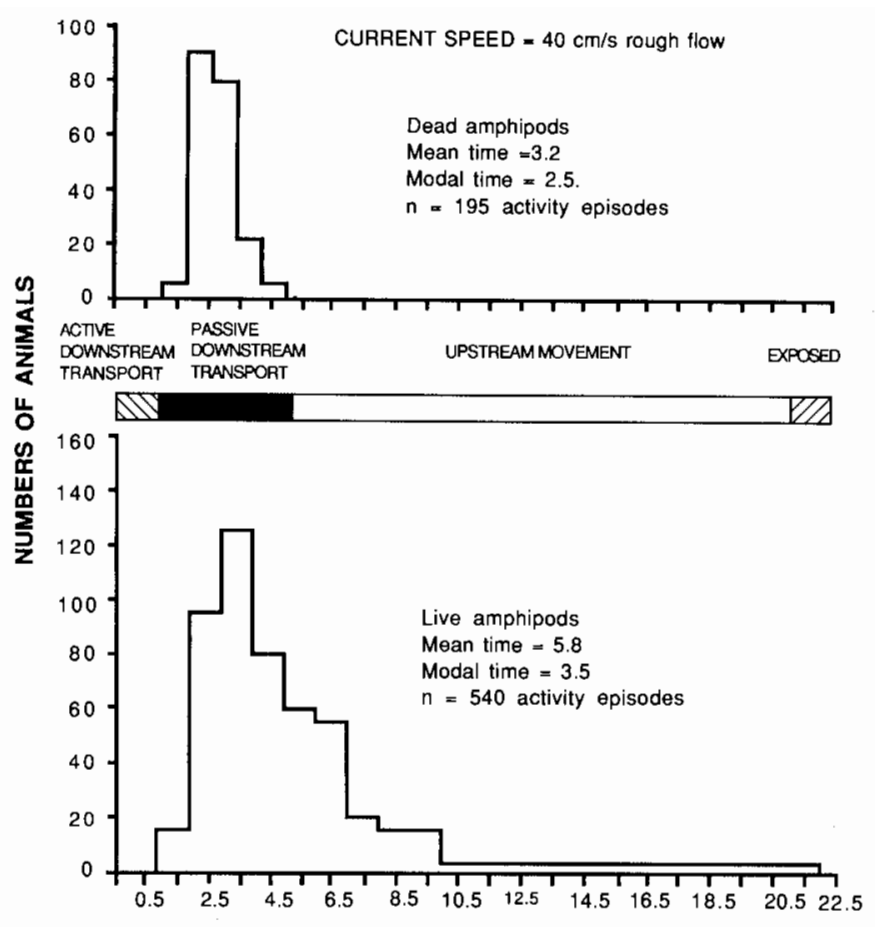

RELATIVE TIME SPENT CROSSING THE LIGHT BEAM

FIG. 6. Frequency distribution of the various times (relative units) taken for single amphipods to pass through the light beam at a current of $40 \mathrm{~cm} / \mathrm{s}$ (rough flow; large stream tanks).

All the above observations were made at night when $G$. pseudolimnaeus is most active. At zero current however the animals showed increased daytime activity (Fig. 8). The modal times taken to pass through the light beam were the same, in both darkness and light ( $>21$ units), indicating that the amphipods spent a considerable amount of time sitting exposed on tank screens. However, the proportion of exposed animals was much greater during the day (3.2 times). During the day, the mean time taken to pass through the beam was $17.0 \pm 0.48$ $( \pm 1 \mathrm{SE})$ units compared with $13.6 \pm 0.23$ at night. These two values were significantly different $(p<0.001, t$-test $)$ indicating that the animals swam faster at night (Table 2). Individual amphipods swam faster in the daytime $(p<0.001, t$-test; Table 2) at current speeds of 15 and $28 \mathrm{~cm} / \mathrm{s}$. At $40 \mathrm{~cm} / \mathrm{s}$, under relatively smooth flow, the animals appeared to swim faster at night, although the daytime data available are limited. At 40 $\mathrm{cm} / \mathrm{s}$, under rough flow, there was no statistically significant difference between day and night swimming speed.

\section{Variation in Drift According to Size of Environment}

Total distance drifted by a single amphipod in one entire drift episode (i.e. the distance covered from the time of entry into the drift to the time of termination) was significantly greater in the large stream tanks than in the small tanks (approximately $31.0 \%$ farther; $p<0.0001, t$-test; Table 3). Similarly, the mean distance drifted before the animals first contacted the tank wall or bottom substrate (but carried on drifting) was greater (83.2\% greater; $p<0.0001, t$-test) in the large tanks. The mean number of times an amphipod touched the tank walls or substrate/centimetre drifted was the same in both small and large tanks (Table $3)$. However, dead animals touched the sides significantly less often $(p<0.005, t$-test) in the large tanks. 
TABLE 1. Summary of treatment conditions.

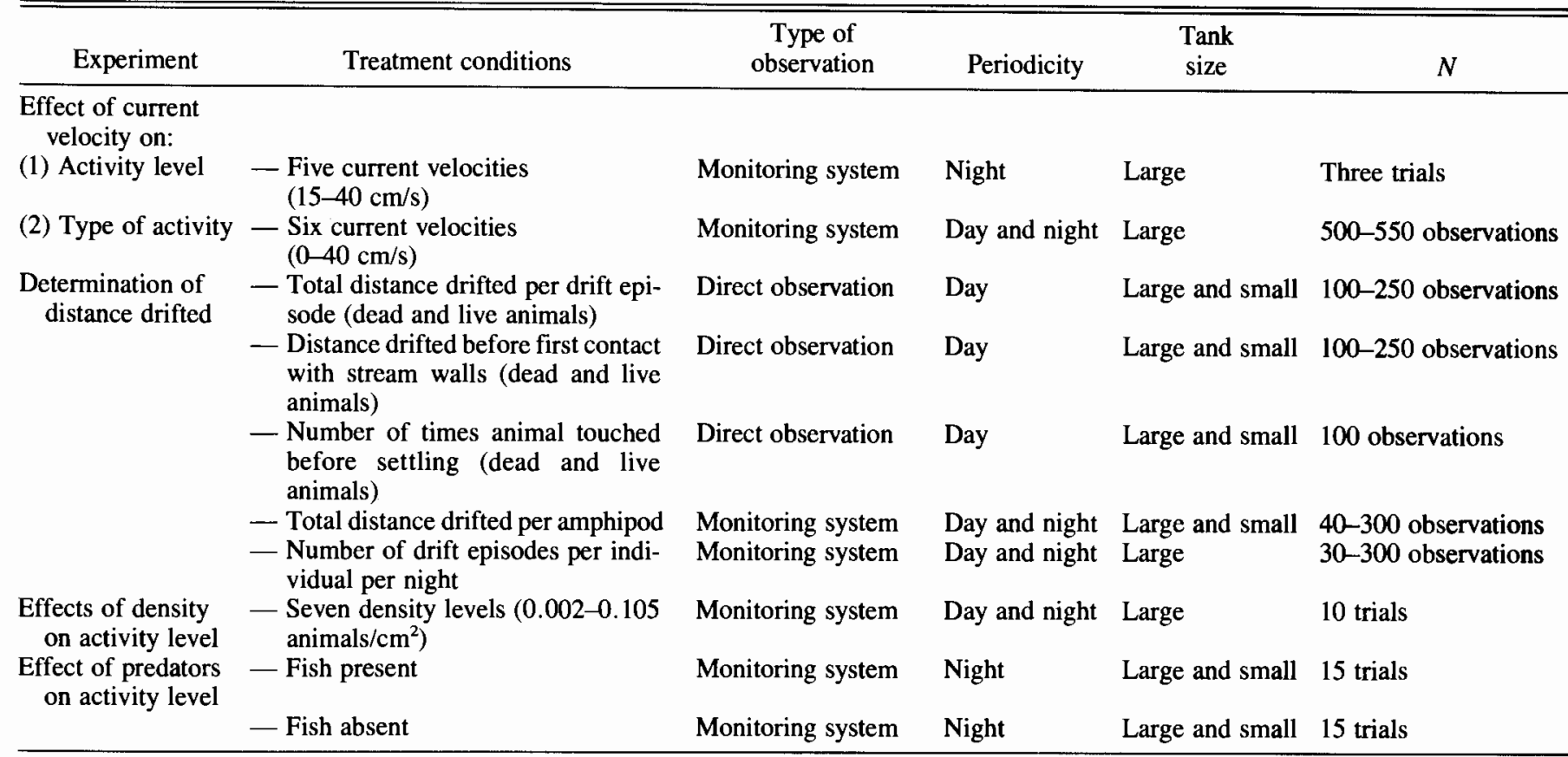

produced on the chart paper. Amphipods moving against the current caused large deflections of the recorder pen (e.g. range 9.0 to $20.5 \mathrm{~cm}$ at $15 \mathrm{~cm} / \mathrm{s}$ ), while those swimming with the current caused much smaller deflections (under $2.5 \mathrm{~cm}$ at 15 $\mathrm{cm} / \mathrm{s}$ ). Wallace et al. (1975) showed that G. pseudolimnaeus were unable to detect ultraviolet light and behaviour was not affected by the beam.

The tanks were illuminated by banks of fluorescent and incandescent lights which provided an illumination of 13.5 $\mu \mathrm{E} \cdot \mathrm{s}^{-1} \cdot \mathrm{m}^{-2}$ under $6 \mathrm{~cm}$ of water during the daylight phase of a 12:12 L:D cycle. There was a substrate of medium-sized gravel in the tanks (mean diameter $=11.0 \mathrm{~mm}$ ) and a water depth of $13 \mathrm{~cm}$. The surface area of the bottom of each large tank was $2068 \mathrm{~cm}^{2}$ compared with $380 \mathrm{~cm}^{2}$ for each of the small tanks.

Amphipods were collected from Balsam Creek, Durham County, Ontario $\left(43^{\circ} 59^{\prime} \mathrm{N}, 79^{\circ} 04^{\prime} \mathrm{W}\right)$. Densities of amphipods (adults of both sexes) per unit area and food in the tanks were kept the same at 20 animals/large tank and four animals/small tank. The diet consisted of pelleted rabbit food, which was readily consumed by $G$. pseudolimnaeus and allowed growth.

The various experimental manipulations are summarized in Table 1

\section{Effect of Current Velocity on Activity}

Activity responses to manipulation of current speed and flow pattern were measured only in the large tanks. Manipulation was achieved by increasing the rotation of the paddle wheel to give currents of 15,28 , and $40 \mathrm{~cm} / \mathrm{s}$. Water flow at these speeds was relatively laminar as determined by the mixing patterns of dye in the water column. At maximum rotation a very rough pattern flow was produced. Measured current speed at this setting was also approximately $40 \mathrm{~cm} / \mathrm{s}$. Nocturnal activity was recorded at each current speed, in three replicate trials of 10 consecutive hours each. Data from the $2 \mathrm{~h}$ around dusk and dawn were not used because of the high variance in counts in these transitional periods (see Fig. 9). Fresh animals were used in each trial.

Since terminology within the drift literature is in a somewhat confused state, we partitioned the activity that we observed into four types: "active downstream transport", "passive downstream transport", "upstream movement", and "exposed", according to the length of time that each animal took to travel through the $1.8-\mathrm{cm}$ diameter light beam of the activity tank, which was recorded by length of lines of trace on the chart. At each current speed, the range of times (in relative units) to traverse the light beam of passively transported animals was defined by measuring the times taken by freshly-killed animals. For example, the range of data (normally distributed) for $15 \mathrm{~cm} / \mathrm{s}$ was (normally distributed) two to eight time units (Fig. 3). Our definition of "passive downstream transport" differs somewhat from that of "passive drift" (e.g. Wiley and Kohler (1984) " . . passive entry is presumably the result of accidental or unintentional release, and subsequent errosion. . .'). Our definition refers solely to how the animals move in the water column with no assumption of motivation behind release from the substrate. Animals undergoing "active downstream transport" were defined as those swimming with the current and passing through the light beam at speeds faster than passively transported animals; in this example, zero to two time units at 15 $\mathrm{cm} / \mathrm{s}$. Animals engaged in "upstream movement" against the current took longer than passively transported animals to cross the light beam (range nine to 20.5 time units). A small percentage of animals sat or crawled on the screens directly under the photocell for periods of $>21$ time units (determined by direct observation). These have been termed "exposed".

\section{Determination of Distances Drifted}

Distances drifted and times spent in the water column were obtained by direct observation of the point of entry into the drift by individual amphipods, the distance to first contact with the tank walls, the number of times the walls were contacted before 
